\title{
Adsorption of Water on Two-Dimensional Crystals: Water/Graphene and Water/Silicatene
}

\author{
Uwe Burghaus
}

Department of Chemistry and Biochemistry, North Dakota State University, Fargo, ND 58108-6050, USA; uwe.burghaus@ndsu.edu; Tel.: +1-701-231-9742; Fax: +1-701-231-8831

Academic Editors: Reshef Tenne and Duncan H. Gregory

Received: 9 March 2016; Accepted: 18 April 2016; Published: 25 April 2016

\begin{abstract}
The adsorption of water on solid surfaces is a scientific evergreen which again recently prompted considerable attention in the materials, nano-, and surface science communities, respectively, due to conflicting evidence presented in the most highly regarded scientific journals. This mini review is a brief and personal perspective of the current literature (and our own data) about water adsorption for two examples, namely graphene and silicatene, which are both two-dimensional (2D) crystals. Silicatene, an inorganic companion of graphene, is intriguing as it presents us with the possibility to synthesize a $2 \mathrm{D}$ analog to zeolites by doping this crystalline silicon film. The wettability by water and whether or not support effects of epitaxial 2D crystals are present is of concern. Regarding applications: some 2D crystals appear promising for the hydrogen evolution reaction, i.e., hydrogen generation from water; a functionalization of graphene (by oxygen/water) to graphene oxide may be interesting for metal-free catalysis; the latest highlight in this field appears to be "icephobicity", an application related to the hydrophobicity of surfaces.
\end{abstract}

Keywords: graphene; silicatene; water; surfaces; kinetics; dynamics; 2D crystals; wetting; hydrophobic; hydrophilic

\section{Introduction and Literature Survey}

\subsection{Why Graphene for Heterogeneous Catalysis?}

Due to quasi mass production of graphene, applications also in catalysis are potentially achievable. However, from a fundamental perspective, the overarching question may be: do graphene's widely praised unique electronic properties also make it useful as a (heterogeneous) catalytic material? It might indeed, but presently nobody knows a definite answer to that question. However, at least two concrete examples already exist in the literature.

The first example are fuel cells [1]. Recently, it was apparently demonstrated that graphene membranes allow for proton transfer, i.e., graphene is permeable for protons (similar to Nafion) [1] However, graphene is impermeable to atoms and molecules (in contrast to Nafion) [1]. Therefore, graphene based catalysts could eliminate the fuel cross-over problem in direct liquid fuel cells, significantly boosting the efficiency. That does not work with HOPG (Highly Oriented Pyrolytic Graphite) or carbon black (graphite powder). The permeability which affects chemistry and surface science applications is certainly related to graphene's unique electronic properties. Obviously, given how well Nafion based technology is established, it would be difficult to propose a change to the engineering community. The fuel cross-over is also not the only problem. However, that is also not the point I try to make here. The example shows that graphene's well-known unique electronic properties can also make it useful in heterogeneous catalysis.

The second even more obvious example is small-molecule gas sensors. The high carrier mobility, conductivity and low intrinsic noise (which are electronic structure properties) promise a high 
signal-to-noise ratio of graphene sensors which can result in high sensitivity [2,3]. Therefore, graphene can be advantageous as a component of small-molecule gas sensors. Performance of gas sensors is affected by the very same properties as reactivity of catalysts.

In the light of these two briefly described examples, one may respond with "yes" to the question "does graphene's unique electronic structure also make it a catalytically useful material?" Therefore, it makes sense to study the basic surface science properties of graphene such as water adsorption in regard of heterogeneous catalysis.

\subsection{Functionalized Graphene and Water Adsorption}

Graphene on its own is not very reactive. Therefore, the next perhaps obvious question may be: how can we enhance the reactivity? Specifically, can a metal-free catalyst be build based on a graphene functionalization, for example, as graphene oxide? Ideally, graphene would directly provide reactive oxygen/oxygenates for surface reactions (ethylene epoxidation, CO oxidation, carbonate formation, etc.). Therefore, the adsorption of water and oxygen on graphene is not just of academic interest.

In basic science studies, the wettability of graphene by water and whether or not support effects of epitaxial 2D crystals are present is being controversially discussed. Briefly, when this topic was originally addressed for the first time, only contact angle measurements were available for graphene. Conclusions reported were contradictory [4-6] and covered the entire range of possible outcomes from transparent graphene (i.e., negligible effect of graphene) [6], partially transparent graphene [5], to "opaque" graphene (i.e., negligible effect of the support) [4]. The term transparent implies that graphene has no effect and one just observes whatever the support would do on its own. All these contact angle measurements were supported by theory, usually molecular dynamics. Moreover, all of these studies were conducted at ambient pressure, usually using chemical vapor deposited (CVD) graphene. Importantly, shortly after these first reports, it was seen in another ambient pressure study [7] that contact angles of water on graphene change over time due to uptake of contaminations from ambient (see also [8]). Actually it is known from rather early surface science work on HOPG [9,10] that the hydrophobicity in particular for graphitic systems depends distinctly on environmental factors. In addition, CVD graphene samples bear the potential risk of a high defect density and may have patches on the surface that may be covered by more than one atomic layer of carbon. When I became aware of the discussion in the literature, the obvious task for a surface chemist was to determine the wetting properties at ultra-high vacuum (UHV), clean, conditions [11,12]; preferentially on higher quality physical vapor deposited (PVD) graphene samples [11].

Water and organic molecules just physisorb on graphitic systems, i.e., their interaction is dominated by van der Waals interactions. Interestingly, according to some theoretical studies [5], part of van der Waals interactions of the support are transmitted through the monatomic graphene layer, i.e., accordingly graphene is partially transparent and support effects are expected. In other words, physisorption on graphene can be substrate mediated and therefore affected by the polarizability of the substrate. How chemisorption (covalent bonding) on graphene would be affected by the support graphene is grown on, has apparently not yet been considered theoretically. It is known that the electron conductivity across graphene is basically zero and only large along the carbon monolayer [1]. Therefore, electron tunneling through graphene would appear to be the only mechanism of direct charge transfer through graphene. Hence, in simple terms, it is plausible that graphene mostly blocks covalent bonding of the substrate (no substrate mediated covalent bonding) as seen, e.g., for benzene adsorption on graphene/Ruthenium [13]. (Benzene dissociates on Ru, but just adsorbed molecularly on graphene/Ruthenium [13]).

As a side note, an interesting and in fundamental studies rather novel topic is the "icephobicity" of surfaces. Superhydrophobic surfaces have apparently been shown to prevent ice accumulation by suppressing nucleation at certain conditions, i.e., this is surface science and related to wetting properties of surfaces [14]. Ice formation is a major cost factor and safety concern in aeronautics. 
Similarly, hydrophobicity affects applications such as desalination using graphene membranes [15]. Thus, fundamental properties of graphene that can be characterized and understood using surface science are indeed relevant for many applications.

\subsection{Inorganic $2 D$ Crystals and Water Adsorption}

The discovery of graphene quickly sparked also the synthesis of inorganic 2D crystals such as silicatene $\left(\mathrm{SiO}_{4}\right)$, molybdenum selenide $\left(\mathrm{MoSe}_{2}\right)$, molybdenum disulfide $\left(\mathrm{MoS}_{2}\right)$, boron nitride $(\mathrm{BN})$, etc. Electronic effects and surface properties of these systems are nearly unexplored. One of the few inorganic adsorbate systems studied in some detail is water/silicatene [16-18]. Inorganic 2D crystals also appear promising for the hydrogen evolution reaction $[19,20]$.

There is no real controversial discussion about water adsorption on silicatene in the literature, but in the few works available on the subject [16-18] it was apparently a priori assumed (by different groups) that 2D silica (silicatene) behaves like bulk silica and must therefore be hydrophobic. This is somewhat astonishingly since firstly, also for amorphous bulk silica surfaces, hydrophilic interactions are known for quite some time [21] (which are induced by defects). Secondly, given the so far accepted molecular structure of silicatene [22,23], hydrophobic and hydrophilic adsorption sites could exist [24]. We recently reinvestigated water adsorption on silicatene [24] and did indeed find hydrophobic and hydrophilic silicatene, depending on the very details of the silicatene synthesis. Therefore, the hydrophobicity could be used as a quality criterion of silicatene samples.

\section{Results and Discussion of Our Own Work}

\subsection{Methodology}

Unfortunately, contact angle measurements with water do not work at UHV, but standard temperature ramping techniques (TDS-thermal desorption spectroscopy) can be applied to characterize fairly directly wetting properties of surfaces at clean conditions.

In a TDS experiment, water is adsorbed at low temperatures onto the sample, mounted in UHV. Afterwards, the surface temperature is raised and desorbing water is simultaneously detected in the gas phase using a mass spectrometer. The result is simply a desorption rate (/water pressure) vs. temperature curve (TDS curve). The experiments are usually repeated for different starting concentrations of water. In so doing, concentration dependent desorption rates are determined. Importantly, for zero-th order kinetics, per definition, the rates are coverage independent which translates into a set of TDS curves with similar initial slopes. Trivially, at large concentrations (and low temperature) any gas condenses on a surface, which always leads to zero-th order desorption kinetics. The clue, however, for a hydrophobic (non-wetting) system, zero-th order kinetics is evident even in the sub-monolayer concentration range. Therefore, if similar initial slopes in TDS data are detected for small water concentrations, the adsorption is very likely hydrophobic. This is fairly simple to detect experimentally (at clean UHV conditions).

In other words, traditionally, the conditions for zero-th order kinetics are fulfilled when a large reservoir is available, (i.e., water evaporation from a river). In case of a hydrophobic system, the "droplets" with large contact angels formed on the non-wetting surface are the reservoir. Water starts to desorb/evaporate from the outer surface of these droplets while the interior acts as a reservoir. Thus, a two phase system is formed similarly to the water evaporation from a river.

Therefore, a simple technique such as TDS can be used to distinguish between hydrophobic and hydrophilic surfaces: zero-th order kinetics at low water concentration (hydrophobic) vs. non zero-th order kinetics (hydrophilic). In addition, in most cases, several TDS peaks are seen for hydrophilic surfaces compared to just one TDS peak for hydrophobic systems. Many surfaces studied in surface science exhibit that behavior. Repeating these experiments for different supports will eventually reveal support effects. 


\subsection{Water Adsorption on Graphene}

Water adsorption kinetics was characterized for graphene/Ru(0001) in UHV [11]. Briefly, as evident from Figure 1, over the entire exposure range, including sub-monolayer (0.6-2.5 L) and multilayer (3.5-15 L) exposures, only a single peak, which is typical for a condensation peak is seen. That result is consistent with a hydrophobic surface. This peak, labeled a C-peak, condensation peak, is identified as such since the low temperature edges line up independent of exposure (/starting coverage), i.e., the desorption rate is independent of coverage. Coverage independent kinetics is per definition zero-order kinetics which is the only kinetics seen here within the entire coverage range. (Only one peak is present.) Moreover, the peak shifts solely to higher temperatures within the entire exposure range (simply because it takes longer to desorb thicker water layers). Therefore, that surface is hydrophobic using that term basically as an equivalent to sub-monolayer zero-order kinetics. As known from prior works [25], the Ru support is hydrophilic, i.e., this system may be called non-transparent. (Hydrophobic graphene adsorbed on hydrophilic substrate.) In addition, studies of this kind on different supports revealed support effects, i.e., graphene is not necessarily always hydrophobic $[11,12,26]$.
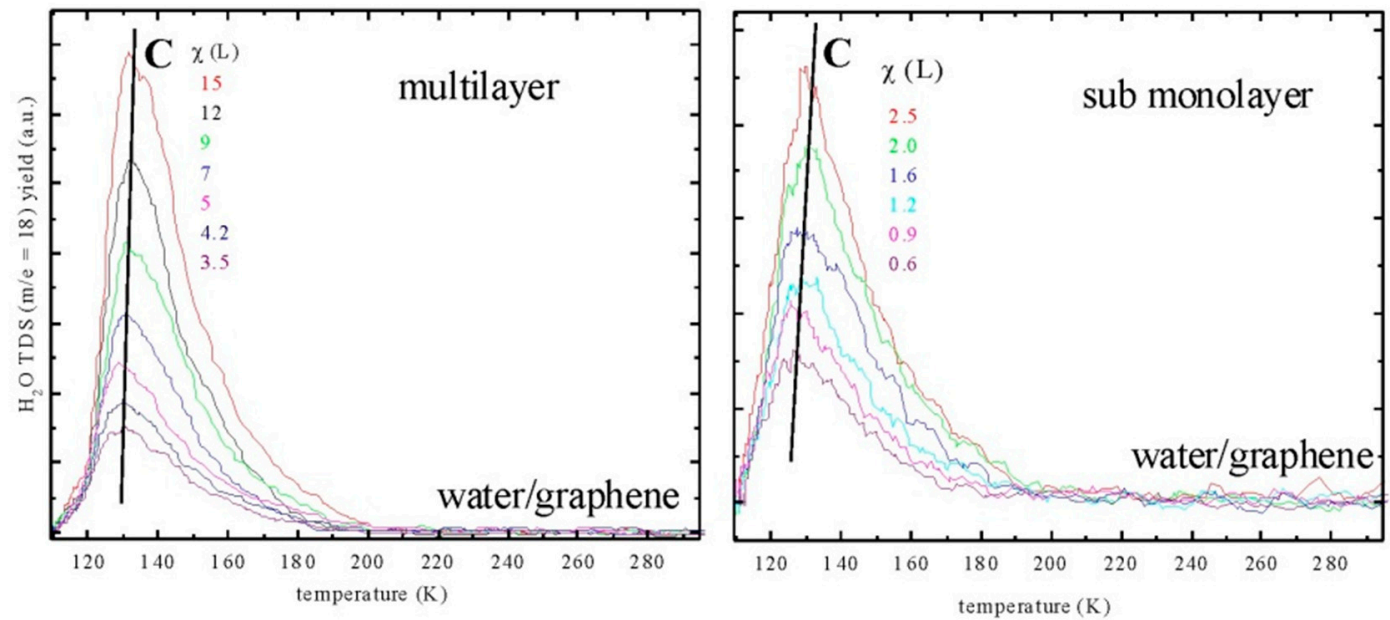

Figure 1. Adsorption of water on physical vapor deposited graphene/Ru(0001), as studied by water thermal desorption spectroscopy (TDS). Condensation peak is labeled as C-peak. Exposure, $\chi(\mathrm{L})$, is given in Langmuir (1 L $=1 \times 10^{-6}$ torr. $\left.\mathrm{s}\right)$. (Data from [11])

\subsection{Water Adsorption on Silicatene}

Water adsorption kinetics was characterized for silicatene/Mo(112) in UHV [24]. Depending on details of the preparation procedure [24], hydrophobic and hydrophilic surfaces can be generated and easily distinguished by TDS. Briefly, as Figure 2 depicts, in one case, the TDS curves resemble all properties of a condensation feature (C-peak) indicative of a hydrophobic surfaces. (See discussion in the last section.) In the other case, the TDS structure is typical for molecular adsorption in the sub-monolayer range ( $\alpha$-peak). The simplest way to distinguish these kinetics here is to recognize that the TDS peaks shift in different directions with increasing exposure (/starting coverage), as indicated by the solid line added as a guide for the eye. A consequence of this, the low temperature edges line up for one data set (left panel), but not for the other one. Also, the hydrophilic silicatene surface does show two TDS peaks at greater exposures which are absent for the hydrophobic system [24]. 

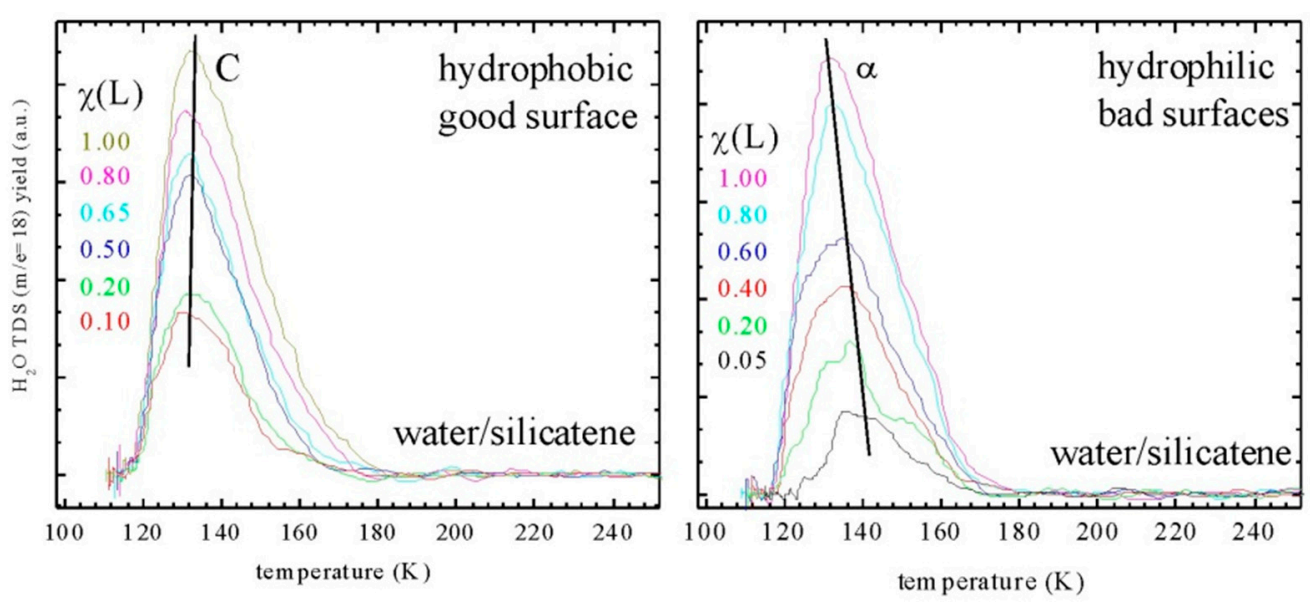

Figure 2. TDS of water on silicatene/Mo(112). Results of two different silicatene preparations (two samples) are shown. $\mathrm{C}$ denotes the condensation peak (C-peak) and $\alpha$ : a monolayer peak (molecular adsorption) ( $\alpha$-peak). Only the most important sub-monolayer exposure range is shown. (Data from [24])

\section{Experimental Section}

For materials science and surface science studies, the most common graphene synthesis is PVD. In ref. [27], we described a PVD synthesis variation that additionally allows for quantifying the defect density. Here, benzene is decomposed on Ru and simultaneously the hydrogen signal measured. The smaller the residual hydrogen desorption, the smaller the defect density. Raman spectroscopy is often described as the tool of choice to determine the quality of graphene samples. Unfortunately, that does not work easily for metallic substrates which cause large background signals in Raman spectra. Many other synthesis procedures are described in the literature [28]. For example, on $\mathrm{SiC}(0001)$ graphene forms by high temperature annealing due to carbon segregation to the surface [29]. CVD graphene samples are commercially available. Graphene on substrates such as silica and glass are usually formed by CVD/copper and subsequent transfer of graphene.

A number of variations of silicatene synthesis procedures can be found in the literature. The process may be considered an inorganic surface science (/thin film) synthesis. For details, see $[21,22]$ from the group that first demonstrated the synthesis and perhaps see the supplemental to [24] Briefly, silicatene can be grown, e.g., on Mo(112) surfaces. First, an oxygen overlayer structure, $\mathrm{Mo}(112)-\mathrm{O}$, (or added row reconstruction) is formed in UHV. Secondly, $\mathrm{Si}$ is deposited on Mo(112)-O. Finally, $\mathrm{Si}$ is oxidized in UHV to form silicatene. In more recent works, the second and last steps were typically combined. The silicatene preparation is time consuming and tricky as compared to the PVD graphene synthesis. For example, too great annealing temperatures induce defects in silicatene. Too low temperatures appear to inhibit a perfect crystallization of the silica film. Similarly, too much $\mathrm{Si}$ (overdosing), results in an amorphous layer rather than in crystalline silicatene. One of the tricks which finally allowed to fabricate crystalline 2D silica films after many unsuccessful attempts is apparently the right starting structure, namely $\mathrm{Mo}(112)-\mathrm{O}$ rather than clean Mo-surfaces. The latter again, results usually in amorphous $\mathrm{Si}$ films, only. Meanwhile, $\mathrm{Pd}(100)$ and $\mathrm{Ni}(111)$ supports have also been used [30,31]. Perhaps the real clue about silicatene is doping it with, e.g., Al, which apparently results in a 2D analog of zeolites [32,33]. Applications demonstrated so far are, however, very limited and little is known about the electronic structure.

\section{Conclusions}

In our opinion, for gas-surface interactions, we have demonstrated that experiments in UHV are required to characterize the intrinsic properties of materials such as graphene. Also, as the silicatene example illustrates, wetting properties are very sensitive towards impurities and defects of 2D crystals. 
Acknowledgments: The Donors of the American Chemical Society and Petroleum Research Fund are acknowledged for partial financial support. Data shown here are part of the thesis projects of Nilushni Sivapragasam and Mindika T. Nayakasinghe as well as the work of a postdoctoral fellow, Ashish Chakradhar. All of them worked at North Dakota State University (NDSU).

Conflicts of Interest: The author declares no conflict of interest.

\section{References}

1. Hu, S.; Lozada-Hidalgo, M.; Wang, F.C.; Mishchenko, A.; Schedin, F.; Nair, R.R.; Hill, E.W.; Boukhvalov, D.W.; Katsnelson, M.I.; Dryfe, R.A.W.; et al. Proton transport through one-atom-thick crystals. Nature 2014, 516, 227-231. [CrossRef] [PubMed]

2. Meng, F.; Guo, Z.; Huang, X. Graphene-based hybrids for chemiresistive gas sensors. Anal. Chem. 2015, 68, 37-44. [CrossRef]

3. Yavari, F.; Koratkar, N. Graphene-based chemical sensors. J. Phys. Chem. Lett. 2012, 3, 1746-1749. [CrossRef] [PubMed]

4. Raj, R.; Maroo, S.C.; Wang, E.N. Wettability of graphene. Nano Lett. 2013, 13, 1509-1503. [CrossRef] [PubMed]

5. Shih, C.J.; Wang, Q.H.; Lin, S.; Park, K.C.; Jin, Z.; Strano, M.S.; Blankschtein, D. Breakdown in the wetting transparency of graphene. Phys. Rev. Lett. 2012, 109, 176101-176109. [CrossRef] [PubMed]

6. Rafiee, J.; Mi, X.; Gullapalli, H.; Thomas, A.V.; Yavari, F.; Shi, Y.; Ajayan, P.M.; Koratkar, N.A. Wetting transparency of graphene. Nat. Mater. 2012, 11, 217-222. [CrossRef] [PubMed]

7. Li, Z.; Wang, Y.; Kozbial, A.; Shenoy, G.; Zhou, F.; McGinley, R.; Ireland, P.; Morganstein, B.; Kunkel, A.; Surwade, S.P.; et al. Graphene wetting. Nat. Mater. 2013, 12, 925-929. [CrossRef] [PubMed]

8. Aria, A.I.; Kidambi, P.R.; Weatherup, R.S.; Xiao, L.; Williams, J.A.; Hofmann, S. Time evolution of the wettability of supported graphene under ambient air exposure. J. Phys. Chem. C 2016, 120, 2224-2229. [CrossRef] [PubMed]

9. Chakarov, D.V.; Osterlund, L.; Kasemo, B. Water adsorption on graphite(0001). Vacuum 1995, 46, 1109-1116. [CrossRef]

10. Chakarov, D.V.; Osterlund, L.; Kasemo, B. Water adsorption and coadsorption with potassium on graphite(0001). Langmuir 1995, 11, 1201-1209. [CrossRef]

11. Chakradhar, A.; Burghaus, U. Adsorption of water on graphene/Ru(0001)—An experimental ultra-high vacuum study. Chem. Commun. 2014, 50, 7698-7702. [CrossRef] [PubMed]

12. Chakradhar, A.; Sivapragasam, N.; Nayakasinghe, M.T.; Burghaus, U. Support effects in the adsorption of water on CVD graphene: An ultra-high vacuum adsorption study. Chem. Commun. 2015, 51, 11463-11468. [CrossRef] [PubMed]

13. Chakradhar, A.; Sivapragasam, N.; Nayakasinghe, M.T.; Burghaus, U. Adsorption kinetics of benzene on CVD graphene: An ultra-high vacuum study. J. Vac. Sci. Technol. A 2016, 34, 021402-021411. [CrossRef]

14. Kreder, M.J.; Alvarenga, J.; Kim, P.; Aizenberg, J. Icephobicity. Nat. Rev. Mater. 2016, 1, 1-23.

15. You, Y.; Sahajwalla, V.; Yoshimurab, M.; Joshi, R.K. Graphene and graphene oxide for desalination. Nanoscale 2016, 8, 117-129. [CrossRef] [PubMed]

16. Kim, Y.D.; Wei, T.; Stultz, J.; Goodman, D.W. Dissociation of water on a flat, ordered silica surface. Langmuir 2003, 19, 1140-1150. [CrossRef]

17. Wendt, S.; Frerichs, M.; Wei, T.; Chen, M.S.; Kempter, V.; Goodman, D.W. The interaction of water with silica thin films grown on Mo(112). Surf. Sci. 2004, 565, 107-113. [CrossRef]

18. Kaya, S.; Weissenrieder, J.; Stacchiola, D.; Shaikutdinov, S.; Freund, H.J. Formation of an ordered ice layer on a thin silica film. J. Phys. Chem. C 2007, 111, 759-765. [CrossRef]

19. Morais, A.; Longo, C.; Araujo, J.R.; Barroso, M.; Durrant, J.R.; Nogueira, A.F. Nanocrystalline anatase $\mathrm{TiO}_{2} /$ reduced graphene oxide composite films as photoanodes for photoelectrochemical water splitting studies: The role of reduced graphene oxide. Phys. Chem. Chem. Phys. 2016, 18, 2608-2618. [CrossRef] [PubMed]

20. Chhetri, M.; Gupta, U.; Yadgarov, L.; Rosentsveig, R.; Tenne, R.; Rao, C.N.R. Beneficial effect of Re doping on the electrochemical HER activity of $\mathrm{MoS}_{2}$ fullerenes. Dalton Trans. 2015, 44, 16399-16407. [CrossRef] [PubMed]

21. Bakaev, V.A.; Steele, W.A. On the computer simulation of a hydrophobic vitreous silica surface. J. Chem. Phys. 1999, 111, 9803-9809. [CrossRef] 
22. Weissenrieder, J.; Kaya, S.; Lu, J.L.; Gao, H.J.; Shaikhutdinov, S.; Freund, H.J.; Sierka, M.; Todorova, T.K.; Sauer, J. Atomic structure of a thin silica film on a Mo(112) substrate: A two-dimensional network of $\mathrm{SiO}_{4}$ tetrahedra. Phys. Rev. Lett. 2005, 95, 076103-076110. [CrossRef] [PubMed]

23. Kaya, S.; Baron, M.; Stacchiola, D.; Weissenrieder, J.; Shaikhutdinov, S.; Todorova, T.K.; Sierka, M.; Sauer, J.; Freund, H.J. Review: On the geometrical and electronic structure of an ultra-thin crystalline silica film grown on Mo(112). Surf. Sci. 2007, 601, 4849-4854. [CrossRef]

24. Nayakasinghe, M.T.; Chakradhar, A.; Sivapragasam, N.; Burghaus, U. Water adsorption on two-dimensional silica films. Appl. Surf. Sci. 2016, 364, 822-829. [CrossRef]

25. Schmitz, P.J.; Polta, J.A.; Chang, S.L.; Thiel, P.A. Isotope effect in water desorption from Ru(001). Surf. Sci. 1987, 186, 219-226. [CrossRef]

26. Parobek, D.; Liu, H. Wettability of graphene. 2D Mater. 2015, 2, 032001-032016. [CrossRef]

27. Chakradhar, A.; Trettel, K.M.; Burghaus, U. Benzene adsorption on Ru(0001) and graphene/Ru(0001)—How to synthesize epitaxial graphene without STM or LEED? Chem. Phys. Lett. 2013, 590, 146-150. [CrossRef]

28. Batzill, M. The surface science of graphene: Metal interfaces, CVD synthesis, nanoribbons, chemical modifications, and defects. Surf. Sci. Rep. 2012, 67, 83-147. [CrossRef]

29. Hossain, Z.; Johns, J.E.; Bevan, K.H.; Karmel, H.J.; Liang, Y.T.; Yoshimoto, S.; Mukai, K.; Koitaya, T.; Yoshinobu, J.; Kawai, M.; et al. Chemically homogeneous and thermally reversible oxidation of epitaxial graphene. Nat. Chem. 2012, 4, 305-307. [CrossRef] [PubMed]

30. Zhang, Z.; Jiang, Z.Q.; Yao, Y.X.; Tan, D.L.; Fu, Q.; Bao, X.H. Silicatene thin films on palladium. Thin Solid Films 2008, 516, 3741-3750. [CrossRef]

31. Kundu, M.; Murata, Y. Silicatene growth on nickel. Appl. Phys. Lett. 2002, 80, 1921-1929. [CrossRef]

32. Stacchiola, D.; Kaya, S.; Weissenrieder, J.; Kuhlenbeck, H.; Shaikhutdinov, S.; Freund, H.J.; Sierka, M.; Todorova, T.K.; Sauer, J. Synthesis and structure of ultrathin aluminosilicate films. Angew. Chem. Int. Ed. 2006, 45, 7636-7641. [CrossRef] [PubMed]

33. Gruendling, C.; Percher, J.A.; Goodman, D.W. Preparation of mixed $\mathrm{Al} / \mathrm{SiO}_{2}$ thin films supported on $\mathrm{Mo}(100)$. Surf. Sci. 1994, 318, 97-112. [CrossRef]

(C) 2016 by the author; licensee MDPI, Basel, Switzerland. This article is an open access article distributed under the terms and conditions of the Creative Commons Attribution (CC-BY) license (http://creativecommons.org/licenses/by/4.0/). 